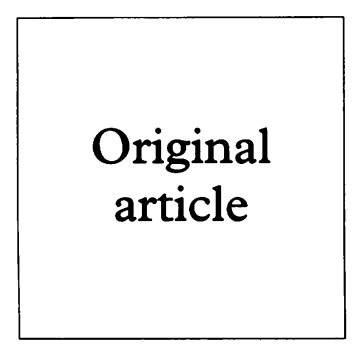

\title{
Sexual behaviour of adolescents before and after the advent of AIDS
}

\author{
Lars Østergaard
}

Objectives: To assess changes in sexual behaviour and use of contraceptive methods in Danish adolescents from the period before the advent of AIDS up to the present.

Design: Comparative study comparing data obtained from two identical cross sectional surveys. Setting: Grenaa Gymnasium, Denmark.

Subjects: 626 high school students in 1982 and 499 high school students in 1996.

Methods: An anonymous standardised self administered questionnaire handed out to high school students at Grenaa Gymnasium in spring 1982. In spring 1996 an identical questionnaire was handed out to every high school student at the same gymnasium.

Main outcome measures: Age at first sexual intercourse, contraceptive use, and reason for choice of contraceptive strategy.

Results: Today more males had experienced the first sexual intercourse before their 16th birthday $(p=0.047)$ compared with 1982 . The reverse held for females $(p=0.003)$. From 1982 to 1996 condom use increased in males with no regular partner $(p=0.009)$. In females with no regular partner, there was during the same period an increase in considering the condom a personal contraceptive method $(p=0.017)$. In 1982 and 1996 protection from sexually transmitted diseases was given as reason for the choice of contraceptive strategy by $21 \%$ and $72 \%$ of males with no regular partner $(\mathrm{p}<0.001)$, and by $7 \%$ and $32 \%$ of males with a regular partner $(p<0.001)$. The corresponding figures for females in 1982 and 1996 were $10 \%$ and $71 \%$ $(\mathrm{p}<0.001)$ for those with no regular partner and $4 \%$ and $21 \%(\mathrm{p}<0.001)$ for those with a regular partner.

Conclusion: Condom use has increased among adolescents with no regular partner brought up under the widespread awareness of AIDS, and the reason for this is to be protected from sexually transmitted diseases. A future decline in the incidence of various sexually transmitted diseases may be expected, and information on safe sexual practices should be continued.

(Genitourin Med 1997;73:448-452)

Keywords: sexual behaviour; adolescents; AIDS

\section{Introduction}

In 1983 AIDS was discovered as a heterosexually transmitted life threatening disease. ${ }^{1}$ Since then there has been public awareness of AIDS and use of condoms for safe sexual practices. This may have contributed to a change in sexual behaviour with time especially for today's adolescents who have been brought up with this widespread awareness of AIDS. Information and education on safe sexual practices are currently the major ways of combatting the emerging worldwide epidemic of sexually transmitted HIV infection, and therefore knowledge of changes in sexual behaviour and contraceptive use with time is important for future prevention strategies. Such information is also important in the prediction of future incidence of other sexually transmitted diseases (STDs).

Only few studies have compared sexual behaviour and contraceptive use before and after the advent of AIDS. ${ }^{2-5}$ Those studies, showing increasing safe sex practices but only minor changes in key sexual behaviour, were, however, limited to women who either consulted gynaecologists or STD clinics. No comparisons have yet been made among adolescents in the community who for their entire school life could have been faced with AIDS.
The purpose of the present study was therefore to assess the changes in sexual behaviour and use of contraceptive methods in high school students from the period before the advent of AIDS up to the present. This was done by comparing data obtained from two identical cross sectional surveys performed at the same high school in 1982 and 1996.

\section{Methods}

DESIGN

An anonymous standardised self administered questionnaire containing information about current regular partner, age at first sexual intercourse, cumulated number of sexual partners, current personal use of contraceptive method(s), and reason(s) for choosing contraceptive strategy was handed out to every high school student at Grenaa Gymnasium in spring 1982. In spring 1996 an identical questionnaire was handed out to every high school student at the same gymnasium. The questionnaires were handed out to the students in each class by a representative of the class and were filled out whenever the students found it most convenient. The questionnaires were returned anonymously in sealed envelopes either by mail or by putting them into boxes placed at the gymnasium with sex and age as 
the only identifiers. A reminder was given orally to all high school students during gatherings at the high school. This study compares the data obtained in these two cross sectional surveys.

\section{POPULATION}

In 1982 the questionnaire was handed out to all the registered 398 females (mean age $17 \cdot 7$ years, median age 17 years) and 228 males (mean age 18.0 years, median age 18 years). The questionnaire was completed by 279 $(70 \cdot 1 \%)$ females and by $118(51 \cdot 8 \%)$ males.

In 1996 the questionnaire was handed out to all the registered 330 females (mean age 18.0 years, median age 18 years) and the registered 169 males (mean age $18 \cdot 1$ years, median age 18 years). The questionnaire was completed by $247(74 \cdot 8 \%)$ females and by 94 $(55 \cdot 6 \%)$ males.

No data on the ethnic, cultural, or religious characteristics of either study population were obtained. However, Danish high school students are a highly homogeneous population in which almost all students are Danish citizens, being white and Protestant. In 1996 four immigrants were registered at the gymnasium (senior master Lars Sloth, personal communication), and there is no reason to believe that the ethnic, cultural, or religious characteristics would have changed substantially from 1982 to 1996.

\section{OUTCOME MEASURES}

The following variables were used to study changes in basic sexual behaviour: percentage reporting a current regular partner, percentage who had experienced their first sexual intercourse before their 16th birthday, and the cumulated number of sexual partners.

The following variables were used to study changes in contraception: the student's own currently used contraceptive method(s) and reason(s) for choosing contraceptive strategy. For evaluation of the latter, sexually experienced students were asked whether they and their partner (if any) had chosen their contraception as a consequence of: (1) protection from STDs, (2) effective birth control, (3) maximal pleasure, (4) frequent intercourse, (5) economic considerations, and (6) freedom from unwanted effects of other methods.

Table 1 Age at first sexual intercourse in 1982 and 1996 among sexually experienced responders

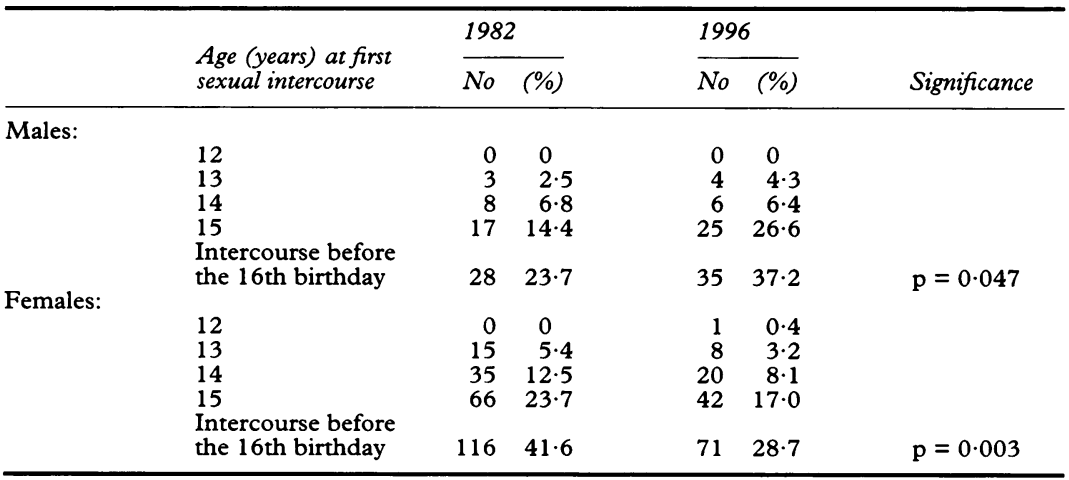

DATA ANALYSIS

Since the exact data regarding age and sex were not known for the non-responding students, the gymnasium's student files were used to assess the age and sex distribution for the entire student body. This was done for each sex by calculating the difference between the year of birth and the respective year of survey.

Data from 1982 were extracted from the survey report prepared at that time (unpublished data). Data from 1996 were manually extracted from the questionnaires and stored in a computer using the Microsoft Excel spreadsheet and the Microsoft Access database.

Calculations were based on the number of responding students (responders) except for data regarding cumulated number of sexual partners and use of contraception, for which calculations were based only on sexually experienced responders. All analyses were made as direct comparisons between data obtained in 1982 and 1996.

Difference in age at first sexual intercourse was assessed by comparing the percentage of females and males who had experienced their first sexual intercourse before their 16th birthday. The potential influence of a discrepancy in age distribution was thus eliminated since all responders had passed their 16th birthday. Assessment of changes in cumulated number of sexual partners was made by comparing the percentage of males and females having had one, two, three to five, six to 10 , or 11 or more partners. In the evaluation of changes in condom use, the percentages of females and males who in each year reported condom use as their own contraceptive method were compared both for students with no regular partner and for students with a regular partner. The percentage of students reporting that they and their partner (if any) had chosen the contraceptive method to avoid STD was used to study the reason for contraceptive strategy.

\section{STATISTICAL METHODS}

Statistical consultation was provided by UNIC, Aarhus, Denmark, and statistical analyses were performed with the $\chi^{2}$ test with Yates's correction and Fisher's exact tests (two tailed). When possible and relevant, the odds ratio for changes in contraceptive use is given. The SAS computer software and EPI INFO 5.0 were used as statistical software programs.

\section{Results}

SEXUAL BEHAVIOUR

Significantly more males had experienced the first sexual intercourse before their 16th birthday in 1996 than in $1982,37 \cdot 2 \% v 23.7 \%$ $\left(\mathrm{p}=0.047, \chi^{2} 3.95\right)$ (table 1$)$. By contrast, the corresponding figures for females were the reverse, $28.7 \% v 41.6 \%\left(p=0.003, \chi^{2} 8.86\right)$ (table 1).

Among males, 68 of the 118 responders $(57 \cdot 6 \%)$ were sexually experienced in 1982 compared with 63 of the 94 responders $(67 \cdot 0 \%)$ in 1996 (not significant). Of the 68 sexually experienced males in 1982, 30 $(44 \cdot 1 \%)$ reported a regular partner, compared 
Table 2 Use of contraception in 1982 and 1996. The data are restricted to what the student considered his or her own method

\begin{tabular}{|c|c|c|c|c|c|c|c|c|c|c|}
\hline \multirow[b]{3}{*}{ Contraceptive method } & \multicolumn{4}{|c|}{ Regular partner } & \multirow[b]{3}{*}{ Significance } & \multicolumn{4}{|c|}{ No regular partner } & \multirow[b]{3}{*}{ Significance } \\
\hline & \multicolumn{2}{|c|}{1982} & \multicolumn{2}{|c|}{1996} & & \multicolumn{2}{|c|}{1982} & \multicolumn{2}{|c|}{1996} & \\
\hline & No & $(\%)$ & No & $(\%)$ & & No & $(\%)$ & No & $(\%)$ & \\
\hline \multicolumn{11}{|l|}{ Males: } \\
\hline Condom & 12 & 40 & 19 & 61 & NS & 23 & 61 & 29 & 91 & $p=0.01$ \\
\hline No current personal use & 18 & 60 & 12 & 39 & & 15 & 39 & 3 & 9 & \\
\hline Sexually experienced males (total) & 30 & 100 & 31 & 100 & & 38 & 100 & 32 & 100 & \\
\hline \multicolumn{11}{|l|}{ Females: } \\
\hline Oral contraception alone & 66 & 53 & 70 & 69 & $p=0.02$ & 30 & 48 & 27 & 35 & NS \\
\hline Condom and oral contraception & 0 & 0 & 5 & 5 & & 0 & 0 & 5 & $6\}$ & -000 \\
\hline Condom alone & 1 & 1 & 1 & $1)$ & NS & 0 & 0 & 2 & $3\}$ & $p=0.02$ \\
\hline Intrauterine device & 12 & 10 & 0 & 0 & $\mathrm{p}=0.004$ & 1 & 2 & 0 & 0 & NS \\
\hline Other & 5 & 4 & 1 & 1 & NS & 6 & 10 & 1 & 1 & NS \\
\hline No current personal use & 41 & 33 & 24 & 24 & NS & 25 & 40 & 43 & 55 & NS \\
\hline Sexually experienced females (total) & 125 & 100 & 101 & 100 & & 62 & 100 & 78 & 100 & \\
\hline
\end{tabular}

Table 3 The impact of being protected against sexually transmitted diseases when choosing contraceptive strategy

\begin{tabular}{|c|c|c|c|c|c|c|c|c|c|c|}
\hline \multirow[b]{3}{*}{ Protection from $S T D s$} & \multicolumn{4}{|c|}{ Regular partner } & \multirow[b]{3}{*}{ Significance } & \multicolumn{4}{|c|}{ No regular partner } & \multirow[b]{3}{*}{ Significance } \\
\hline & \multicolumn{2}{|c|}{1982} & \multicolumn{2}{|c|}{1996} & & \multicolumn{2}{|c|}{1982} & \multicolumn{2}{|c|}{1996} & \\
\hline & No & $(\%)$ & No & $(\%)$ & & No & (\%) & No & $(\%)$ & \\
\hline \multicolumn{11}{|l|}{ Males: } \\
\hline $\begin{array}{l}\text { Impact on the chosen strategy } \\
\text { No impact on the chosen strategy } \\
\text { Sexually experienced males (total) }\end{array}$ & $\begin{array}{r}2 \\
28 \\
30\end{array}$ & $\begin{array}{r}7 \\
93 \\
100\end{array}$ & $\begin{array}{l}10 \\
21 \\
31\end{array}$ & $\begin{array}{r}32 \\
68 \\
100\end{array}$ & $p=0.03$ & $\begin{array}{r}8 \\
30 \\
38\end{array}$ & $\begin{array}{r}21 \\
79 \\
100\end{array}$ & $\begin{array}{r}23 \\
9 \\
32\end{array}$ & $\begin{array}{r}72 \\
28 \\
100\end{array}$ & $\mathrm{p}<0.001$ \\
\hline \multicolumn{11}{|l|}{ Females: } \\
\hline $\begin{array}{l}\text { Impact on the chosen strategy } \\
\text { No impact on the chosen strategy } \\
\text { Sexually experienced females (total) }\end{array}$ & $\begin{array}{r}5 \\
120 \\
125\end{array}$ & $\begin{array}{r}4 \\
96 \\
100\end{array}$ & $\begin{array}{r}27 \\
74 \\
101\end{array}$ & $\begin{array}{r}27 \\
73 \\
100\end{array}$ & $\mathrm{p}<0.001$ & $\begin{array}{r}6 \\
56 \\
62\end{array}$ & $\begin{array}{r}10 \\
90 \\
100\end{array}$ & $\begin{array}{l}55 \\
23 \\
78\end{array}$ & $\begin{array}{r}71 \\
29 \\
100\end{array}$ & $\mathrm{p}<0.001$ \\
\hline
\end{tabular}

with $31(49 \cdot 2 \%)$ of the 63 sexually experienced males in 1996 (not significant).

Among females, 187 of the 279 responders $(67.0 \%)$ in 1982 and 179 of the 247 responders $(72.5 \%)$ in 1996 were sexually experienced (not significant). Of the 187 sexually experienced females in $1982,125(66.8 \%)$ reported a regular partner, compared with 101 of the 179 $(56.4 \%)$ sexually experienced females in 1996 (not significant).

In 1982, all students who reported a regular partner were also sexually experienced. In 1996, seven students reported having a regular partner without being sexually experienced.

No difference in the numbers of cumulated sexual partners in 1982 and 1996 was observed for either sex (data not shown). The data set from 1982 does not allow a comparison of the cumulated number of sexual partners with regard to regular partner.

\section{USE OF CONTRACEPTIVE METHODS}

Data regarding use of contraceptive methods are shown in table 2 . The question was restricted to what the student considered as his/hers own method. The percentage of condom users among sexually experienced males who did not report a regular partner increased significantly from $61 \%(23 / 38)$ in 1982 to $91 \%$ $(29 / 32)$ in $1996(\mathrm{p}=0.009$ OR $=6.395 \% \mathrm{CI}$ 1.5-37.1) (table 2). A non-significant trend towards more condom users among males who had a regular partner was seen. The proportion of sexually experienced females with no regular partner who reported condom use as their own personal contraceptive method also increased from zero (0/62) in 1982 to $9 \%(7 / 78)$ in 1996 ( $p=0.017$ Fisher's exact test) (table 2). In 1996, six females with a regular partner consid- ered condoms to be their own contraceptive method, compared with one in 1982 (not significant). In 1982, more females with a regular partner used intrauterine contraceptive devices (IUDs) compared with $1996,10 \% v$ zero ( $\mathrm{p}=$ 0.004 Fisher's exact test). The reverse held for oral contraception, which was used by significantly more females with a regular partner in 1996 than in $1982,69 \% v 53 \%(\mathrm{p}=0.02)$ (table 2).

The impact of being protected from STDs when choosing contraceptive strategy increased dramatically from 1982 to 1996 . Of males with a regular partner, $7 \%$ in 1982 and $32 \%$ in 1996 had chosen their contraceptive strategy as protection from STDs $(\mathrm{p}=0.03$ OR $=6.795 \%$ CI 1.2-66.9) (table 3); the corresponding figures for males with no regular partner were $21 \%$ \% $72 \% \quad(\mathrm{p}<0.001$ OR $=9.695 \%$ CI 2.8-33.9) (table 3). The same held for females who had a regular partner, $4 \%$ v $27 \%$ $(p<0.001$ OR $=8.895 \%$ CI $3 \cdot 1-30 \cdot 1)$ and females with no regular partner $(10 \%$ v $71 \%)$ $(p<0.001 \quad O R=22.3 \quad 95 \%$ CI $7.9-70.4)$ (table 3 ). The figures in table 3 cannot be directly compared with the figures in table 2 , since the students in table 3 were asked why they (and their partner, if any) had chosen the contraceptive method, whereas in table 2 the questions concerned only the student's personal use of contraception.

\section{Discussion}

This comparative study on changes in sexual behaviour and use of contraceptive methods among high school students from 1982 to 1996 showed that today more males and females with no regular partner use condoms 
and the reason for this is protection from sexually transmitted diseases. More males and fewer females in 1996 experienced their first sexual intercourse before their 16th birthday, compared with 1982; no other changes in basic sexual behaviour were observed.

The generalisability of the results obtained among Danish high school students to other demographic groups in the society may be questioned. However, the rates of females using oral contraception and no contraception in 1982 (51\% and $35 \%$, respectively) are very close to findings from 1984 among a representative sample of all Danish females aged 16 to 20 years, $47 \%$ and $37 \%$, respectively. ${ }^{6}$ Furthermore, the observed changes in contraceptive use are being reflected in various surrogate markers such as changes in the county's prevalence of $C$ trachomatis infection ${ }^{7}$ and the number of condoms purchased.

The marked increase in use of safe sexual practices during recent years has also been shown in various other settings. ${ }^{2-5}$ 8-10 Today females also consider condoms to be their own contraceptive method, compared with 1982 . These findings are supported by another Danish study ${ }^{11}$ in which $6 \%$ of females reported having condoms in their luggage when travelling. Another noticeable change is that females at present use both oral contraception and condoms as their method of contraception. This may reflect that, in addition to effective birth control, a method that offers protection against STDs is also warranted.

The use of IUDs by females with a regular partner has declined. The reason for this is apparently not to be protected from STDs since the number of oral contraceptive users in this group has increased by the same number. Instead, the increased risk of pelvic inflammatory disease using IUDs, ${ }^{12}$ the appearance of oral contraceptives with better safety profiles, and changing practices among general practitioners may be explanations.

In a Swedish study, $99 \%$ of adolescents knew that condoms gave protection against STDs. ${ }^{13}$ It is therefore likely that the majority of the students reporting condom use also considered the protection against STD when choosing contraceptive strategy, but the condom may have been chosen for other reasons. Thus, still in $199628 \%$ of males and $29 \%$ of females with no regular partner did not think protection against STDs was important when choosing contraceptive strategy. Thus, continued, or even improved, education is needed.

The data on contraceptive use cannot be compared between females and males since Danish females tend to choose male partners older than themselves, ${ }^{14}$ and it is therefore unlikely that the adolescent girls in this study would find their partners among the males in this study.

Lunau and Sonne reported that, in $1968 / 69,7 \%$ of male and $7 \%$ of female Danish high school students had experienced their first sexual intercourse before their 16th birthday. ${ }^{15}$ The considerable increase in 1982 to $24 \%$ and $42 \%$, respectively, was followed in 1996 by a further increase for males to $37 \%$, but by a decrease to $29 \%$ for females. Another Danish study found no change in age at sexual debut between 1984 and $1989,{ }^{10}$ but no data for the period 1989 to 1996 were found. Since the number of lifetime partners remained constant for females over the years, promiscuity might have increased in today's females since their sexual debut is delayed. However, the females were slightly older in 1996 than in 1982 , and this may have contributed to an overestimation of lifetime partners in 1996 For the other studied variables this difference in "chronological age" may be less important compared with the "psychological age", which is probably identical for sexually experienced females attending the high school in 1982 and in 1996.

Unchanged key sexual behaviour has also been observed by DeBuono et al ${ }^{5}$ who compared college women consulting gynaecologists in 1975 and 1989, Evans et $a l^{3}$ who compared data from women attending an STD clinic in 1982 and 1992, and Klanger et al who compared sexual behaviour of Swedish adolescents in the late 1980 s with the late 1970s. ${ }^{16}$

Safe sex practices have been adopted by today's high school students brought up during the widespread awareness of AIDS, especially among those who do not have a regular partner. Fewer females and more males now experience their first sexual intercourse before their 16th birthday, but other sexual behaviour seems not to have changed substantially. Education on safe sex practices should be continued, and a future decrease in STDs may be expected.

I am grateful to Max Adelsböll, Lars Andersen, Poul Hummelshøj, and Lars Sloth for collection of data, and to D John Sellors, St Joseph's Community Health Centre, Hamilton, Ontario, Canada, for valuable comments on the manuscript.

The work was supported by a grant from chairman Jacob Madsen's and Hustru Olga Madsen's Foundation and the Danish AIDS Foundation.

Conflict of interests: None

1 Immunodeficiency among female sexual partners of males with acquired immunodeficiency syndrome (AIDS) New York. MMWR 1983;31:697-8.

2 Evans BA, McCormack SM, Bond RA, MacRae KD. Trends in sexual behaviour and HIV testing among women presenting at a genitourinary medicine clinic during the advent of AIDS. Genitourin Med 1991;67:194-8.

3 Evans BA, McCormack SM, Kell PD, Parry JV, Bond RA MacRae KD. Trends in female sexual behaviour and sexually transmitted diseases in London, 1982-1992. ually transmitted diseases in

4 van Haastrecht HJ, van den Hoek JA, Coutinho RA. Evidence for a change in behaviour among heterosexuals in Amsterdam under the influence of AIDS. Genitourin Med 1991;67:199-206.

5 DeBuono BA, Zinner SH, Daamen M, McCormack SM Sexual behaviour in 1975,1986 , and 1989. $N$ Engl $\mathcal{M} M e d$ 1990;322:821-5.

6 Wielandt H, Wermuth L, Pedersen MR. Contraceptive use in a sample of young Danish females. Acta Obstet Gynecol Scand 1988;67:319-21.

7 Møller JK, Østergaard L, Hansen JT. Clinical evaluation of four non-related techniques for detection of Chlamydia trachomatis in endocervical specimens. Immun Infect Dis 1994;4:191-6.

8 Stigum H, Magnus P, Veierod M, Bakketeig LS. Impact on sexually transmitted disease spread of increased condom use by young females, 1987-1992. Int $\mathcal{F}$ Epidemiol 1995 use by young

9 Herlitz C. Sexual behaviour in the general population of Sweden. Soc Sci Med 1993;36:1535-40.

10 Wielandt HB, Jeune B. Has the age at sexual debut changed after the Safe Sex Campaign? Ugeskr Laeger 1992;154:271-5.

11 Worm AM, Lillelund $\mathrm{H}$. Condoms and sexual behaviour of young tourists in Copenhagen. AIDS Care 1989;1:93-6. 
12 Vessey MP, Yeates D, Flavel R, McPherson K. Pelvic inflammatory disease and the intrauterine device: findings in a large cohort study. Br Med f Clin Res Ed 1981; ings in a lar

13 Persson E, Jarlbro G. Sexual behaviour among youth clinic visitors in Sweden: knowledge and experiences in an HIV perspective. Genitourin Med 1992;68:26-31.

14 Wielandt $\mathrm{H}$, Boldsen J, Jeune B. Age and partners at first intercourse among Danish males and females. Arch Sex Behav 1989;18:449-54.

15 Lunau I, Sonne O. En analyse af gymnasiasters seksuelle vaner [An analysis of sexual habits in high-school students]. Copenhagen, Denmark: Medicinsk forlag, 1971.

16 Klanger B, Tyden T, Ruusuvaara L. Sexual behaviour among adolescents in Uppsala, Sweden. $\mathcal{f}$ Adolesc Health 1993;14:468-74. 